Chapter 5

\title{
Removal of COD by Two-Chamber Microbial Fuel Cells
}

\author{
Katalin Belafi-Bako, Balazs Vajda, Peter Bakonyi and \\ Nandor Nemestothy
}

Additional information is available at the end of the chapter

http://dx.doi.org/10.5772/58373

\section{Introduction}

Microbial fuel cells (MFC) are regarded as special bio-electrochemical systems which seem to have a high potential in the future technology for energy production in the section of renewable green energy sources [1-5].

A classical MFC in general [4-8] consist of an anodic and cathodic chamber divided by a proton (cation) selective membrane (Figure 1). Microbes in the anodic cell - mostly attached to the electrode surface forming a biofilm - oxidize the substrates and generate electrons and protons in the process. Then electrons are transported from the anode to the cathode through an external circuit (wire) resulting measurable electric current. Meanwhile protons are passing through the membrane and enter the cathode cell where they combine with oxygen to form water.

MFC-s can be operated by either monoculture (e.g. Geobacter sulfurreducens [5], Shewanella oneidensis, Lactococcus lactis [9], Lysinibacillus sphaericus [10]) - where the electrogenic species release electron to the anode electrode directly or with the use of electroactive metabolites -, or multiculture (microbe consortia) system, which can be found in e.g. anaerobic sewage sludge acting in a similar way. The substrates of the MFCs operated by sewage sludge can be provided from various wastewaters, thus electricity generation in the MFCs can be coupled with the degradation of organic matters even e.g. wastewater treatment processes [11-20].

Many types of wastewaters were investigated (e.g. beer brewery wastewater [22], food industrial wastewaters $[22,23])$ where the degradation can be followed by COD removal determination [14]. In MFCs applied for treatment of organic matters, the feed can be enriched with various substrates. It has been noted that non-fermentable substrates are superior to fermentable substrate as the electron donor for power output and electron recovery. E.g. it was reported that an acetate enriched MFC produced higher power output than a glucose enriched 


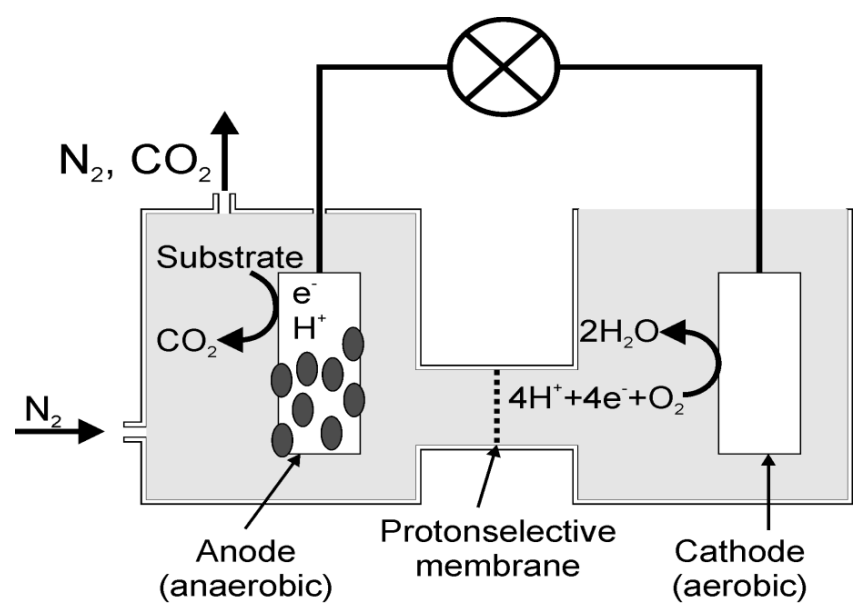

Figure 1. The scheme of a two-chamber microbial fuel cell

MFC [24, 25]. In contrast we found that certain carbohydrate substrates resulted in higher electricity generation [26]. Wastewaters from a sugar beet factory obviously consists of carbohydrates (mono-and/or disaccharides), which are probably suitable enrichments compounds for MFCs.

One of the application segments where extremely promising possibilities are visualised is the integration of the MFCs into wastewater treatment, since these systems are capable to consume organic material even from waste streams to produce power.

In Kaposvar (a city in Southern Hungary) there is a sugar factory, where saccharose (crystallized sugar) is produced from sugar beet [27]. It is an energy intensive process, thus the company has to make great efforts to optimise energy and resource usage, trying to apply environmentally sound, sustainable and waste minimising technologies, which cover water and air quality management as well as usage of by-products. Regarding air quality, the factory has taken extensive measure to decrease dust, smell and sound emissions in recent years, modern biofilters were installed. As to the water issue, special attention is payed to clean the wastewater streams generated during the manufacturing process. The by-products of the processes: the green leaves of sugar beet, the pressed slices (pulp) and other substances are used as components of fertilizers, soil conditioners and for other purposes.

In this factory the processing of all the by-product and waste streams is carefully designed and performed. The leadership of the factory felt responsibility to operate the plant according to environmental safe conditions, therefore they completed the sugar technology with composting - to handle the green parts of the plant -, with a wastewater treatment plant and recently even a biogas fermenter was installed (Figure 2). Inserting microbial fuel cells into this system direct electric power could be produced by reduction of the COD from the waste streams. 


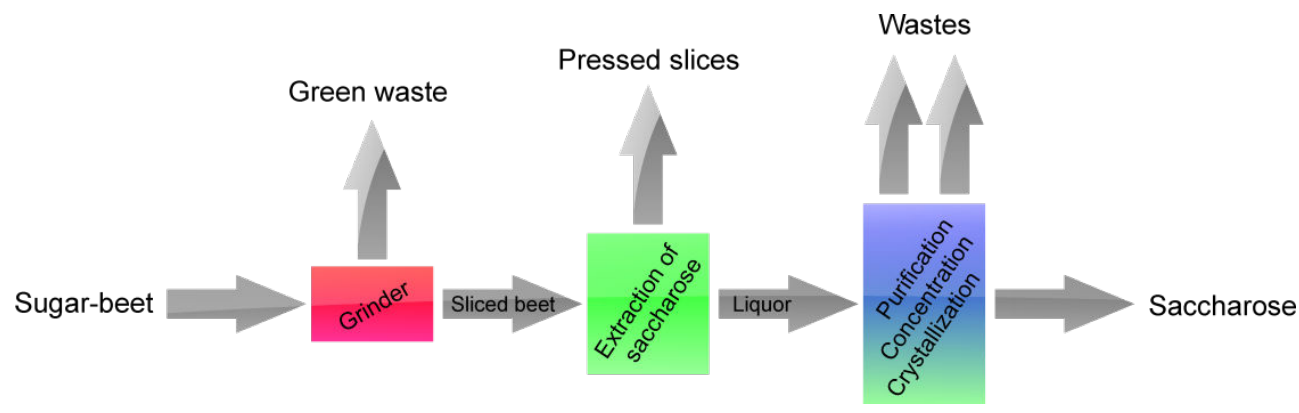

Figure 2. The main process streams in the factory

In this project the aim was to find out how to work and operate a two chamber microbial fuel cell by using wastewater from the sugar beet factory.

\section{Materials and methods}

A two-chamber MFC was used in the experiments (Figure 3). Both cells have a $240 \mathrm{~cm}^{3}$ volume, the membrane between them was a Nafion N115 proton selective membrane, its surface area was $50 \mathrm{~cm}^{2}$ and thickness was $125 \mu \mathrm{m}$. In the anodic cell a complex mesophilic anaerobic sludge (from a local working biogas plant, initial COD value was $70000 \mathrm{mg} / \mathrm{dm}^{3}$ ), while in the cathodic cell distilled water was used. Both electrodes were carbon cloth, their surface area was $50 \mathrm{~cm}^{2}$. The electrodes were connected via a resistor and the voltage data were continuously quantified by a parallel measuring system. It contained a $100 \mathrm{M} \Omega$ resistor and the voltage data were directly collected by a data acquisition device (National Instruments USB-6008/6009). The data were recorded by the LabVIEW program. Based on the voltage and resistance data the current values were calculated, thus the electric power (in $\mathrm{mW}$ units) was possible to provide. The cumulated electricity data were summarized (in $\mathrm{mWh}$ ) taken into account the operating time.

The anaerobic sludge applied in the anodic cell was pretreated prior to usage, as it was reported [26]. The MFC was placed in a thermostated container, where the liquids in both cells were possible to circulate and stir. In the cathodic cell air was entered continuously by a pump to ensure aerobic environment, while $\mathrm{N}_{2}$ was sparged through the anodic cell to assure the anaerobic conditions. The MFC reactor was initially inoculated with the pretreated anaerobic sludge. Then the microbial consortia started to operate in the cell and they were allowed to adapt the actual conditions and colonise locally.

To follow the processes various analytical methods: $\mathrm{pH}$, total solid substance (TSS), COD were applied. COD values of the samples taken from the cells were determined by the potassium dichromate method, which is based on the following oxidation reaction in acidic environment:

$\mathrm{K}_{2} \mathrm{Cr}_{2} \mathrm{O}_{7}+4 \mathrm{H}_{2} \mathrm{SO}_{4}=\mathrm{K}_{2} \mathrm{SO}_{4}+\mathrm{Cr}_{2}\left(\mathrm{SO}_{4}\right)_{3}+4 \mathrm{H}_{2} \mathrm{O}+3 \mathrm{O}$ 


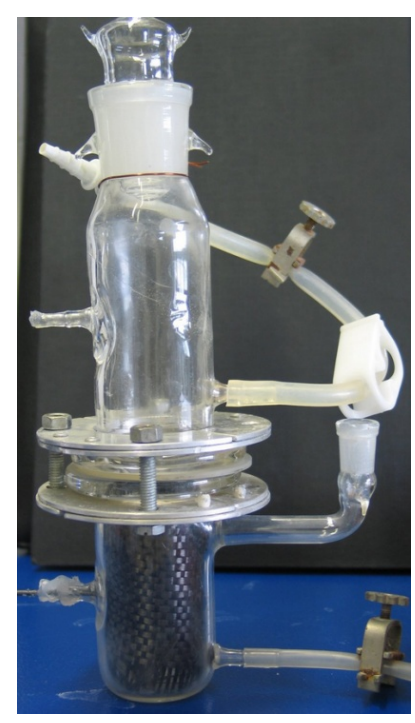

Figure 3. The picture of MFC used

The organic substances in the samples were ravaged in the presence of potassium dichromate and catalysts $\left(\mathrm{AgSO}_{4}, \mathrm{HgSO}_{4}\right)$ in sulphuric acid solution at $145^{\circ} \mathrm{C}$. The absorbance of the chromium (III) ions from the reduction of $\mathrm{K}_{2} \mathrm{CrO}_{7}$ during the oxidation process was determined by a spectrophotometer (Hach LANGE DR 3900) at $600 \mathrm{~nm}$. The COD values of the samples were calculated using a calibration curve taken in the range of $750-4000 \mathrm{KOI} \mathrm{mg} / \mathrm{cm}^{3}$.

\section{Results}

\subsection{Experiments with model wastewater}

To test the behaviour of the MFC, model substrates were used for the experiments. The composition of the model mixture - similar to the waste stream of the sugar beet factory - was carbohydrates $(0.6 \%)$ and inorganic substances (ash, $3 \%)$.

The MFC operation was started by inoculation with the pretreated anaerobic sludge, then the processes were followed by recording the voltage data continuously (Figure 4). A $10 \Omega$ resistor was used in the circuit. After certain intervals $100 \mathrm{~cm}^{3}$ fresh substrate was added (marked by the arrows) to the system to maintain the carbohydrate concentration. These additions mean $9000 \mathrm{mg} / \mathrm{cm}^{3}$ COD input each.

The voltage data have shown that the substrate addition enhanced the power generation and quite high voltage (current density) values were achieved (in the range of 10 and $24 \mathrm{mV}$ ). 


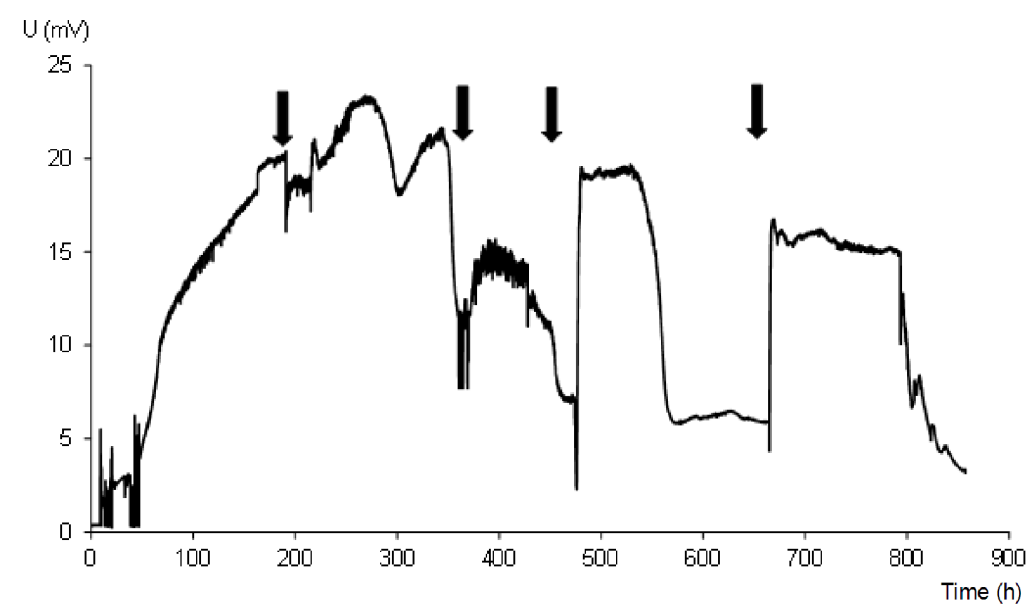

Figure 4. Power generation using model waste water

Samples were taken regularly and the COD values, $\mathrm{pH}$ and TSS were determined. The data are summarised in Tables 1 and 2 .

\begin{tabular}{cccc}
\hline Time $(\mathbf{h})$ & COD $\left(\mathbf{m g} / \mathbf{d m}^{3}\right)$ & COD decrease (\%) \\
\hline $1-192$ & Adding substrate & End of period & 75 \\
\hline $192-336$ & 19800 & 4900 & 61 \\
\hline $336-480$ & 7150 & 2775 & 39 \\
\hline $480-650$ & 5025 & 3075 & 66 \\
\hline $650-880$ & 5325 & 1810 & 69 \\
\hline
\end{tabular}

Table 1. Changes of COD values using model waste stream

\begin{tabular}{ccc}
\hline Time $(\mathbf{h})$ & pH & TSS $\left(\mathbf{g} / \mathbf{d m}^{3}\right)$ \\
\hline 1 & 6.70 & 35.9 \\
\hline 192 & 8.25 & 3.9 \\
\hline 336 & 7.65 & 1.9 \\
\hline 480 & 7.55 & 1.6 \\
\hline 650 & 7.05 & 1.1 \\
\hline 880 & 4.45 & 0.9 \\
\hline
\end{tabular}

Table 2. TSS and $\mathrm{pH}$ values using model waste stream 
As it can be seen remarkable TSS and COD decrease could be observed during the processes, while electric power was generated continuously. The drop in the $\mathrm{pH}$ at $880 \mathrm{~h}$ has shown that the operation of the MFC should be ceased due to the unfavourable biochemical processes. The values of current density, J (normalized to the $50 \mathrm{~cm}^{2}$ carbon cloth electrode) and power density (calculated from the current density and voltage data; Pa and Pm, normalized to the surface of the carbon cloth electrode and the membrane surface area, respectively), moreover the cumulated energy data $\sum \mathrm{P}$ (taken into account the time period of the experiment) are summarized in Table 3.

\begin{tabular}{ccccc}
\hline Time $(\mathrm{h})$ & $\mathbf{J}\left(\mathbf{m A} / \mathbf{m}^{2}\right)$ & $\mathbf{P}_{\mathrm{a}}\left(\mathbf{m W} / \mathrm{m}^{2}\right)$ & $\mathbf{P}_{\mathbf{m}}\left(\mathbf{m W} / \mathrm{m}^{2}\right)$ & $\sum \mathbf{P}\left(\mathbf{m W h} / \mathbf{m}^{2}\right)$ \\
\hline $1-192$ & 260 & 3.380 & 4.023 & 649.0 \\
\hline $192-336$ & 416 & 8.652 & 10.300 & 1245.9 \\
\hline $336-480$ & 220 & 2.420 & 2.880 & 4114.0 \\
\hline $480-650$ & 240 & 2.880 & 3.428 & 4896.0 \\
\hline $650-880$ & 300 & 4.500 & 5.357 & 1035.0 \\
\hline
\end{tabular}

Table 3. Results obtained using model waste stream

The values have shown that notable power density was achieved during the operation and finally altogether more than 10 thousands $\mathrm{mWh} / \mathrm{m}^{2}$ energy was generated by consuming the organic substances from the model waste water in the MFC.

\subsection{Polarization curve}

Our next purpose was to determine the polarization curve using the adapted microbe consortia (grown up in the experiments by the model wastewater). Therefore a serial of experiments were carried out applying various resistances (in the range of 5 and $500 \Omega$ ) built in the system and the voltage/current data were measured (Figure 5). Moreover the power density values were calculated.

It can be seen from the figure that voltage data decreased gradually as higher resistances were installed into the system up to $12 \mathrm{~mA}$ current, thus the MFC was in a stationer state in the given range from electrochemical point of view. With the growing resistance values, however, increasing power density values were possible to achieve, which mean that it is advisable to use higher resistances for the further measurements. The results shown in the Figure are similar as reported in literature [22].

\subsection{Experiments with industrial wastewater}

Wastewater from the sugar factory in Kaposvar was used in the next experiments of our work. It consisted of carbohydrates (others than saccharose: mainly glucose and fructose; altogether $0.6 \%$ ) and ash $3 \%$. The other features of the waste water were: $\mathrm{pH} 5.4, \mathrm{TSS} 34.8 \mathrm{~g} / \mathrm{dm}^{3}$ and COD value $12075 \mathrm{mg} / \mathrm{dm}^{3}$. 


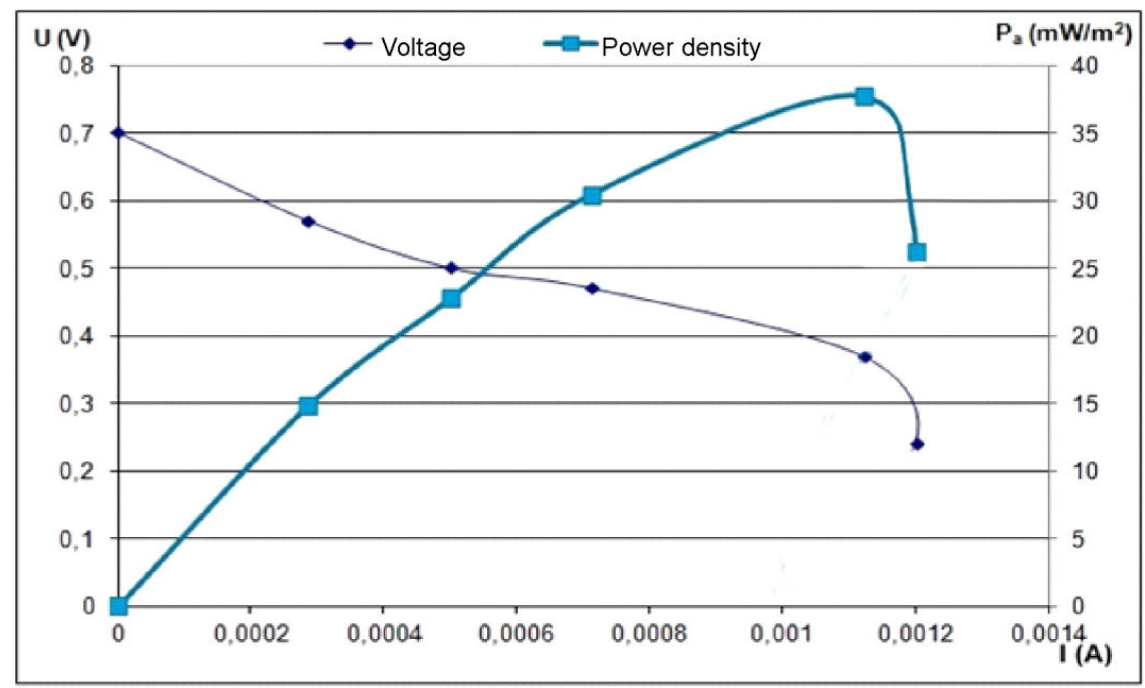

Figure 5. The variance of the voltage and power density in different resistances

Now the MFC was operated by a $330 \Omega$ resistance built in the circuit, which was considered as a more effective operation condition point according to the polarization curve. The adapted microbial consortium was used to inoculate the cell. After certain intervals $100 \mathrm{~cm}^{3}$ fresh substrate (wastewater) was added (marked by the arrows) to the system. In Figure 6 the voltage data obtained in the MFC by the waste water from the sugar beet factory are presented.

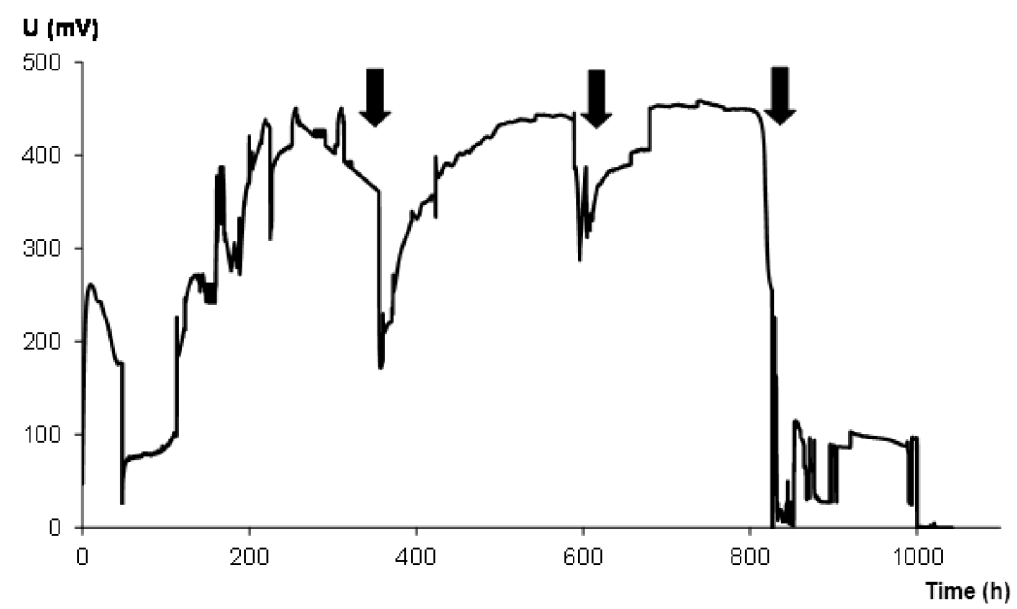

Figure 6. Power generation using industrial waste water from Kaposvar 
The changes of COD values of the samples were determined and summarized in Table 4, while the TSS and $\mathrm{pH}$ data are shown in Table 5.

\begin{tabular}{cccc}
\hline Time $(\mathbf{h})$ & COD $\left(\mathbf{m g} / \mathbf{d m}^{3}\right)$ & decrease of COD (\%) \\
\hline \multirow{2}{*}{ Adding substrate } & End of period & \\
\hline $330-600$ & 21850 & 13850 & 37 \\
\hline $600-840$ & 13673 & 5225 & 50 \\
\hline $840-1000$ & 7795 & 3875 & 26 \\
\hline
\end{tabular}

Table 4. Changes of COD values using waste water from the factory

\begin{tabular}{ccc}
\hline Time $(\mathbf{h})$ & pH & TSS $\left(\mathbf{g} / \mathbf{d m}^{3}\right)$ \\
\hline 1 & 8.1 & 34.8 \\
\hline 330 & 8.0 & 10.8 \\
\hline 600 & 7.6 & 3.2 \\
\hline 840 & 7.1 & 2.5 \\
\hline 1000 & 4.1 & 4.2 \\
\hline
\end{tabular}

Table 5. TSS and $\mathrm{pH}$ values using industrial wastewater

The values of current density, power density - which are higher here than in case of model waste water due to the higher resistance - and the cumulated energy data $\sum \mathrm{P}$ are listed in Table 6.

\begin{tabular}{ccccc}
\hline Time $(\mathbf{h})$ & $\mathbf{J}\left(\mathbf{m A} / \mathbf{m}^{2}\right)$ & $\mathbf{P}_{\mathrm{a}}\left(\mathbf{m W} / \mathbf{m}^{2}\right)$ & $\mathbf{P}_{\mathbf{m}}\left(\mathbf{m W} / \mathbf{m}^{2}\right)$ & $\sum \mathbf{P}\left(\mathbf{m W h} / \mathbf{m}^{2}\right)$ \\
\hline $1-330$ & 181 & 52 & 59.5 & 17160 \\
\hline $330-600$ & 242 & 95 & 113 & 25650 \\
\hline $600-840$ & 245 & 99.2 & 118.2 & 23808 \\
\hline $840-1000$ & 51 & 4.2 & 5.0 & 642 \\
\hline
\end{tabular}

Table 6. Results obtained using industrial waste stream

The current and power density values were outstanding compared to literature data [20-22] or the values obtained with the model wastewater. Altogether more than 60 thousands $\mathrm{mWh} /$ $\mathrm{m}^{2}$ energy was generated during the over 800 hour operation. In the last interval (after 840 hour) the substrate addition did not result in any increase of voltage data, moreover the $\mathrm{pH}$ 
decreased sharply, showing that the biochemical processes in the MFC have not been working properly any longer, thus the operation was ended.

\section{Conclusion}

A two-chamber MFC was designed and built in our laboratory where carbon cloth (fibres) were used as electrodes and Nafion 0125 protonselective membrane was placed between the two cells. Pretreated anaerobic sludge from a local biogas plant was applied in the anode chamber. Experiments with model and industrial wastewaters from a sugar beet factory were carried out to study the efficiency and stability of the system and to measure the electric power generated. It has turned out that it was possible to generate bioelectricity from the particular wastewater and the power data obtained were found similar or higher to the data published in literature, i.e. comparable performance was achieved in our MFC system. Our next purpose is to study the MFC for longer term operation, even in continuous mode of operation, so that we can insert the MFC into the processing scheme of the sugar beet factory [28].

\section{Acknowledgements}

This work was supported by the European Union and co-financed by the European Social Fund in the frame of the TAMOP-4.2.2.A-11/1/KONV-2012-0071 and TÁMOP-4.2.2.A-11/1/ KONV-2012-0038 projects; and the János Bolyai Research Scholarship of the Hungarian Academy of Sciences.

\section{Author details}

Katalin Belafi-Bako*, Balazs Vajda, Peter Bakonyi and Nandor Nemestothy

*Address all correspondence to: bako@almos.uni-pannon.hu

University of Pannonia, Veszprem, Hungary

\section{References}

[1] B.E. Logan: Microbial fuel cells, Wiley \& Sons, New York, 2008

[2] www.microbialfuelcell.org

[3] Y. Mohan, S.N. Muthu Kumar, D. Das: Electricity generation using microbial fuel cells, Int. J. Hydrogen En. 33 (2008) 423-426 
[4] K. Rabaey, W. Verstraete: Microbial fuel cells: novel biotechnology for energy generation, Trends in Biotechnology, 23 (2005) 291-298

[5] D.R. Bond, D.R. Lovley: Electricity production by Geobacter sulfurreducens attached to electrodes, Appl. Env. Microbiol. 69 (2003) 1548-1555

[6] B.E. Logan, J.M. Regan: Electricity-producing bacterial communities in microbial fuel cells, Trends in Microbiology, 14 (2006) 512-518

[7] B.E. Logan: Microbial fuel cells - Challenges and Applications, Environmental Science and Technology 40 (2006) 5161-5586

[8] M. Zhou, T. Jin, Z. Wu, M. Chi, T. Gu: Mirobial fuel cells for bioenergy and bioproducts, Green Energy and Technology 62 (2012) 131-171

[9] M.A. Rosenbaum, H.Y. Bar, Q.K. Beg, D. Segré, J. Booth, M.A. Cotta, L.T. Angenent: Shewanella oneidensis in a lactate-fed pure-culture and a glucose-fed co-culture with Lactococcus lactis with an electrode as electron acceptor, Bioresource Technology 102 (2011) 2623-2628

[10] A. Nandy, V. Kumar, P. P. Kundu: Utilization of proteinaceous materials for power generation in a meidatorless microbial fuel cell $\mathrm{b}$ a new electrogenic bacteria Lysinibacillus sphaericus VA5, Enzyme and Microbial Technology 53 (2013) 339-344

[11] A.K. Mungray, Z.V.P. Murthy, A.J. Tirpude: Post treatment of up-flow anaerobic sludge blanket based sewage treatment plant effluents: A review, Desalination and Water Treatment 22 (2010) 220-237

[12] H. Moon, I.S. Chang, B.H Kim: Continuous electricity production from artificial wastewater using a mediator-less microbial fuel cell, Bioresource Technology 97 (2006) 621-627

[13] Z. Du, H. Li, T. Gu: A state of the art review on microbial fuel cells: A promising technology for wastewater treatment and bioenergy, Biotechnology Advances 25 (2010) 464-482

[14] H. Moon, S.I. Chang, K.K. Jang, B.H. Kim: Residence time distribution in microbial fuel cell and its influence on COD removal with electricity generation, Biochemical Engineering Journal 27 (2005) 59-65

[15] D.H. Park, J.G. Zeikus: Improved fuel cell and electrode designs for producing electricity from microbial degradation, Biotechnol. Bioeng. 81 (2003) 348-355

[16] D.K. Daniel, B.D. Mankidy, K. Ambarish, R. Manogary: Construction and operation of a microbial fuel cell for electricity generation from wastewater, Int. J. Hydrogen En. 34 (2009) 7555-7560

[17] I. Ivanov, L. Ren, M. Siegert, B.E. Logan: A quantitative method to evaluate microbial electrolysis cell effectiveness for energy revovery and wastewater treatment, In. J. Hydrogen Energy 38 (2013) 13135-13142 
[18] R.A. Rozendal, H.V,M. Hamalers, K. Rabaey, J. Keller, C.J.N. Buisman: Towards practical implementation of bioelectrochemical wastewater treatment, Trends in Biotechnology 26 (2008) 450-459

[19] G. Velvizhi, R. K. Goud, S.V. Mohan: Anoxic bio-electrochemical system for treatment of complex chemical wastewater with simultaneous bioelectricity generation, Bioresource Technology, 151 (2014) 214-220

[20] Y. Tian, C. Ji, K. Wang, P. Le-Clech: Assessment of an anaerobic membrane bio-electrochemical reactor for wastewater treatment and energy recovery, J. Membrane Sci., 450 (2014) 242-248

[21] Q. Wen, Y. Wu, D. Cao, L. Zhao, Q. Sun: Electricity generation and modelling of microbial fuel cell from continuous beer brewery wastewater, Bioresource Technology 100 (2009) 4171-4175

[22] B Cercado-Quezada, M. L. Delia, A. Bergel: Testing various food-industry wastes for electricity production in microbial fuel cell, Bioresource Technology 101 (2010) 2748-2754

[23] X. M. Li, K. Y. Cheng, J.W.C. Wong: Bioelectricity production from food waste leachate using microbial fuel cells: Effect of $\mathrm{NaCl}$ and $\mathrm{pH}$, Bioresource Technology 149 (2013) $452-458$

[24] D. Pant, G. van Bogaert, L. Diels, K. Vanbroekhoven: A review of the substrates used in microbial fuel cells (MFCs) for sustainable energy production, Bioresource Technology 101 (2010) 1533-1543

[25] Y. Yuan, S. Zhou, N. Xu, L. Zhuang: Electrochemical characterization of anodic biofilm enriched with glucose and acetate in single-chamber microbial fuel cells, Colloid and Surfaces B: Biointerfaces 82 (2011) 641-646

[26] Bélafi-Bakó, K., Vajda, B., Nemestóthy, N.: Study on operation of a microbial fuel cell using mesophilic anaerobic sludge, Desalination and Water Treatment, 35 (2011) $222-226$

[27] www.agrana.hu

[28] D. Akman, K. Cirik, S. Ozdemir, B. Ozkaya, O. Cinar: Bioelectricity generation in continuously-fed microbial fuel cell: Effects of anode electrode material and hydraulic retention time, Bioresource Technology 149 (2013) 459-464 
